\title{
PACHYDERMOPERIOSTOSIS: UNUSUAL CAUSE OF CLUBBING
}

Paru Priyadarshini ${ }^{1}$, S. Murugan ${ }^{2}$, V. Mahalakshmi ${ }^{3}$, S. Anandan ${ }^{4}$, R. Sudha ${ }^{5}$

\section{HOW TO CITE THIS ARTICLE:}

Paru Priyadarshini, S. Murugan, V. Mahalakshmi, S. Anandan, R. Sudha. "Pachydermoperiostosis: Unusual Cause of Clubbing". Journal of Evolution of Medical and Dental Sciences 2014; Vol. 3, Issue 58, November 03;

Page: 13195-13198, DOI: 10.14260/jemds/2014/3755

ABSTRACT: A 26 year old male presented with characteristic skin features of pachydermoperiostosis such as clubbing of digital and pachydermia.

KEYWORDS: Pachydermoperiostosis, pachydermia; clubbing.

INTRODUCTION: Pachydermoperiostosis (PDP) is a primary hypertrophic osteoarthropathy, characterized by various clinical expressions with the involvement of digital clubbing, pachydermia, seborrhoea, periostosis and arthritis or arthralgia. PDP is also commonly known as Tourine-SolenteGole syndrome. Here, we report a 26 year old man with the diagnosis of complete form of PDP.

CASE REPORT: A 26 years old male came with the complaints of asymptomatic swelling of hand and feet for two years duration. History of thickening of skin over the hands and feet, with excessive sweating of palms and soles. History of increased oiliness over the face. History of recurrent folliculitis on the face was present in the past. No history of congenital heart disease, pulmonary and gastrointestinal disorders. No history of consanguineous marriage. No family history of swelling of digits and bony changes.

On physical examination, grade IV clubbing of the finger and toe nails (figure 1, 2, 3) and no cyanosis was present. On cutaneous examination, patient had mild furrowing and thickening of the forehead with greasy face (figure 4). Multiple pityriasiform plaques and macules present over back, chest and thighs. Bilateral symmetrical enlargement of the lower legs, forearms, palms and soles with spade like hands were present (figure 3, 5, 6).Significant palmar and plantar thickening and hyperhidrosis. Scalp was normal. Systemic examination is normal. Secondary sexual characteristics were well-developed.

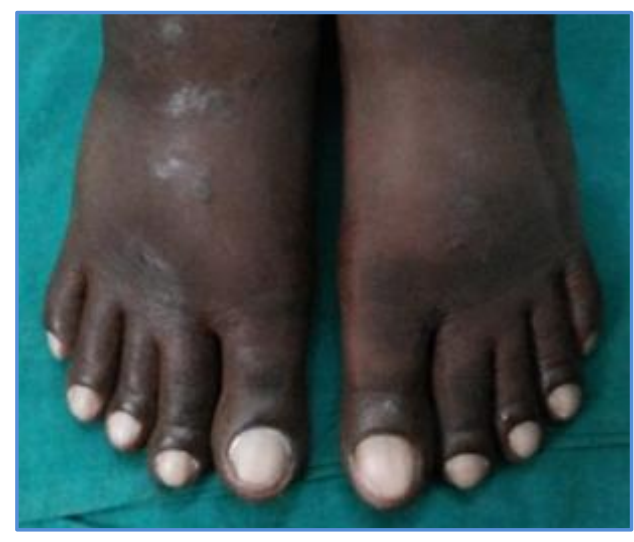

Figure 1

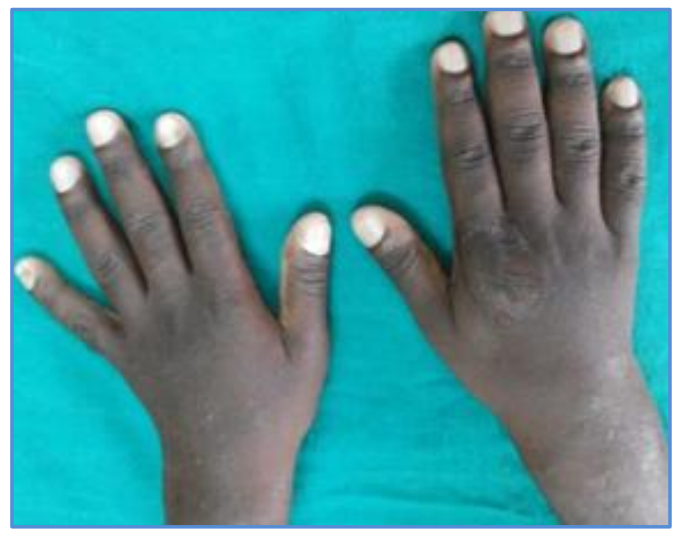

Figure 2 


\section{CASE REPORT}

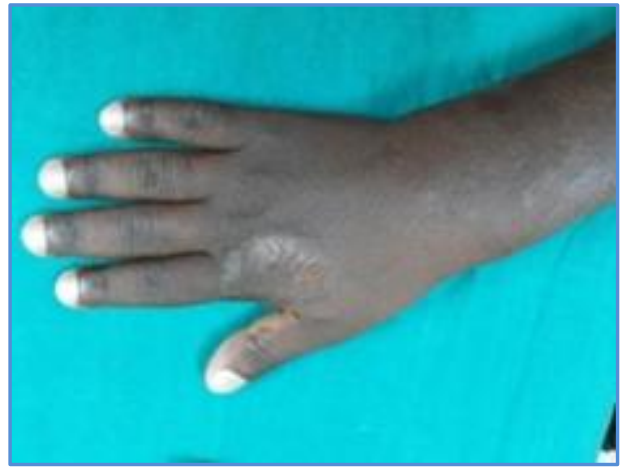

Figure 3

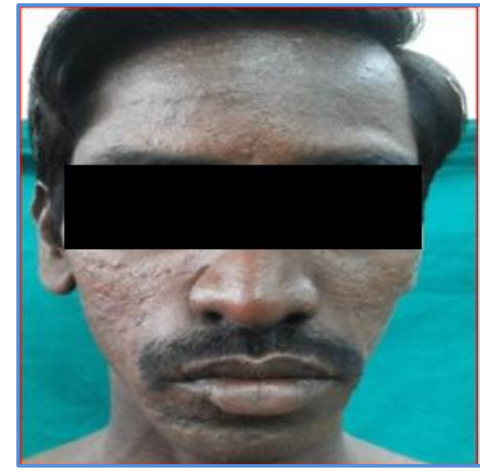

Figure 4

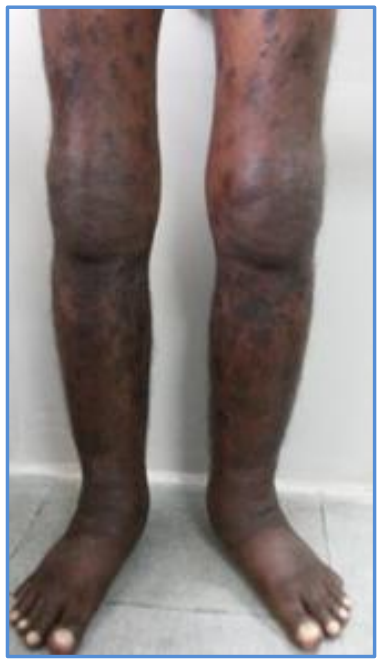

Figure 5

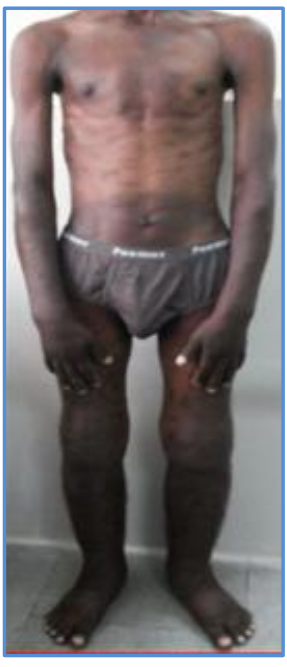

Figure 6

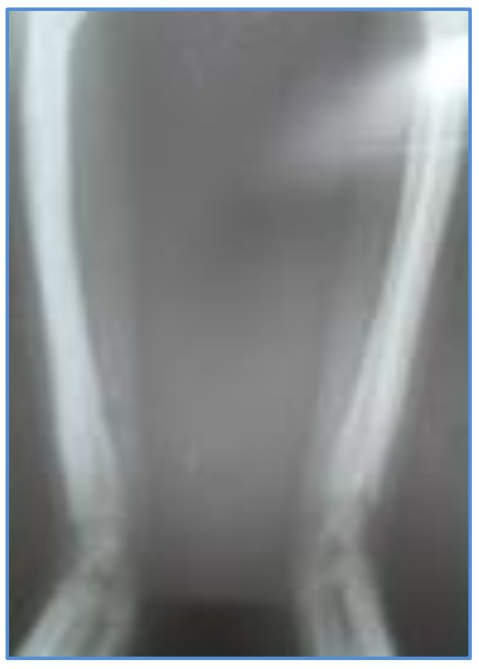

Figure 7

Laboratory investigations, such as complete blood count, urine analysis, liver function test, blood sugar, serum electrolytes, thyroid profile and growth hormone level were normal. Ultrasound abdomen and pelvis were normal. X -ray shows periosteal thickening of diaphysis of long bones, metacarpals and metatarsals (figure 7).

Skin biopsy showed hypertrophy of epidermis, appendages and collagen, an increase of mucopolysaccharide. Malignancy workup and chest X ray was normal. Based on clinical features, radiological and histopathological findings, patient was diagnosed as complete form of pachydermoperiostosis. Patient was started on oral retinoids in view of seborrhea. Reassurance was given and advised for regular follow-up.

DISCUSSION: Pachydermoperiostosis or primary hypertrophic osteoarthropathy is a rare hereditary disorder, which was first described by Friedreich in 1868.1,2 Matucci-cerinic et al. in 1991 proposed diagnostic criteria for PDP i) major criteria: digital clubbing, periostosis, and pachydermia and ii) 
minor criteria: seborrhea, hyperhidrosis, folliculitis, arthritis or arthralgia, gastritis or gastric ulcer, acro-osteolysis, neurovegetative syndrome, hypertrophic gastropathy and cutis verticis gyrate.3,4

PDP has 3 forms: complete form has periostosis and pachydermia, an incomplete form has abnormalities in bone and decreased or absent pachydermia and 'forme fruste' has marked pachydermia and minimum or decreased bone changes. ${ }^{2}$ Pachydermoperiostosis is a familial disorder, inherited autosomal dominant pattern. The male to female ratio is around 7:15.This condition typically appears by infancy, childhood and adolescence, progresses to certain years and then it stabilizes. Pachydermia - skin thickening affects the face and striking feature is cutis vertices gyrata.

Patients sometimes present with others features such as folliculitis, seborrhoea, acne, hyperhidrosis of palms and soles, reduced facial and pubic hair., ${ }^{2,6}$ A patient with skeletal abnormality leads to bone pain and asymmetric arthritis.1,2 Radiological studies show, periosteal thickening of the diaphysis of all long bones, metacarpal and metatarsal bones. ${ }^{7}$ The secondary form of PDP, occurs due to from cardiopulmonary, gastrointestinal, hepatic disease and malignancy. ${ }^{1,5,7}$

In our case, patient did not have any other associated systemic disease. Some malignant conditions associated with PDP such as epidermoid carcinoma, myelofibrosis, and gastric adenocarcinoma. Other conditions like crohn's disease hypertrophic gastritis and peptic ulcer.2,8,9

PDP is a self-limiting disease. ${ }^{3}$ For increased seborrhoea, oral retinoids (Isotretinoin) are helpful by inhibiting the sebaceous hyperplasia and reducing thickness and oiliness of the face. ${ }^{2,3}$ Nonsteroidal anti-inflammatory drugs are useful for bony pain. ${ }^{3}$ However there is no favorable and possible documented long- term medical treatment available. Regular follow-up is necessary for early detection of these abnormalities.

\section{REFERENCES:}

1. Bhaskaranand K, Shetty RR, Bhat AK. Pachydermoperiostosis: Three case reports. J Orthop Surg 2001; 9:61-6.

2. Santos-Duran JC, Yuste-Chaves M, Pachydermoperiostosis (Touraine-Solente-Gole syndrome), Actas Dermosifilioggr. 2007; 98: 116-20.

3. Yi-jeng Tsai, Ming-Tuo Chaun, Pachydermoperiostosis, Dermatol Sinica 18: 156-162, 2000.

4. Matucci-Cerinic M, Lotti T, Jajic I, et al: The clinical spectrum of pachydermoperiostosis (primary hypertrophic osteoarthropathy). Medicine 70: 208-214, 1991.

5. AG Sasane, Pachydermoperiostosis, MJAFI 2010; 66: 387-388.

6. Auger M, Stavrianeas N. Pachydermoperiostosis. Orphanet Encyclopedia. 2004; April, 1-8.

7. Resnick D. Enostosis, Hyperostosis and periostitis: In Resnick D, Kransdorf MJ, editors. Bone and Joint imaging. $3^{\text {rd }}$ ed. Philadelphia: Elsevier Saunders; 2005; 1433-5.

8. Ikeda $\mathrm{F}$, Okada $\mathrm{H}$, et al. Pachydermoperiostosis associated with juvenile polyps of the stomach and gastric adenocarcinoma. J Gastroenterol. 2004; 39: 370-4.

9. Bachmeyer C, Blum L, Cadranel JF. Myelofibrosis in a patient with pachydermoperiostosis. Clin Exp Dermatol. 2005; 30: 646-8. 


\section{AUTHORS:}

1. Paru Priyadarshini

2. S. Murugan

3. V. Mahalakshmi

4. S. Anandan

5. R. Sudha

\section{PARTICULARS OF CONTRIBUTORS:}

1. Resident, Department of Dermatology, Sri Ramachandra University.

2. Professor, Department of Dermatology, Sri Ramachandra University.

3. Professor, Department of Dermatology, Sri Ramachandra University.

4. Professor, Department of Dermatology, Sri Ramachandra University.
5. Professor, Department of Dermatology, Sri Ramachandra University.

\section{NAME ADDRESS EMAIL ID OF THE CORRESPONDING AUTHOR:}

Dr. Paru Priyadarshini, \# 4E, Block III,

Prabhancha Apartments,

Mathakovil Street, Thoraipakkam,

Chennai-97.

Email: puppy2804@gmail.com

Date of Submission: 21/10/2014.

Date of Peer Review: 22/10/2014.

Date of Acceptance: 25/10/2014.

Date of Publishing: 03/11/2014. 